\title{
O legado da cooperação científica entre o curso de Serviço Social da PUC-SP e escolas portuguesas
}

The legacy of scientific cooperation between the PUC-SP Social Work course and portuguese schools

\author{
Kathiuscia Freitas Coelho ${ }^{a}$ \\ (1) https://orcid.org/0000-0002-1952-7633 \\ Olegna de Souza Guedesa \\ (D) http://orcid.org/0000-0001-7559-7225
}

Resumo: A relação entre o Serviço Social brasileiro e o português se intensificou em determinados momentos da trajetória sócio-histórica da profissão nos dois lados do continente. O presente artigo destaca o momento em que foram firmados os protocolos de cooperação científica entre a Pontifícia Universidade Católica de São Paulo e as escolas portuguesas, o qual representou relevante contribuição para o reconhecimento do Serviço Social como licenciatura em Portugal na década de 1980.

Palavras-chave: Formação Profissional. Termo de Cooperação Científica, Brasil, Portugal.
Abstract: The relationship between Brazilian and Portuguese Social Work was intensified at certain moments in the socio-historical trajectory of the profession on both sides of the continent. This article highlights the moment when scientific cooperation protocols were signed between the Pontifical Catholic University of São Paulo and Portuguese schools, that represented a relevant contribution to the recognition of Social Work as a degree in Portugal in the 1980s.

Keywords: Professional Training. Scientific Cooperation Term, Brazil, Portugal. 


\section{Introdução}

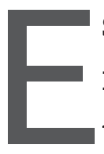

ste artigo, escrito por meio de revisão bibliográfica e documental, retoma parte de análises desenvolvidas em tese de doutorado que trata da relação entre o Serviço Social brasileiro e o português, da sua gênese à contemporaneidade da profissão em ambos os países. Procurou-se, na construção do artigo, delimitá-lo a um dos objetivos que orientaram a pesquisa de doutorado: apresentar aspectos que revelam a importância de protocolos de cooperação científica entre o curso de Serviço Social da Pontifícia Universidade Católica (PUC) de São Paulo e escolas portuguesas, iniciados na década de 1980.

Optou-se por apresentar o artigo em dois tópicos. Em um primeiro tópico, apresentam-se aspectos da trajetória sócio-histórica do Serviço Social em Portugal, que são similares a aspectos da trajetória dessa profissão no Brasil, haja vista, sobretudo, a influência da Igreja Católica e aspectos ideopolíticos marcados por períodos políticos autocráticos em ambos os países e experiências, ainda que pontuais, de lutas políticas frisadas por enfrentamentos a esses ciclos autoritários. Em um segundo tópico, apresentam-se aspectos que caracterizam o intercâmbio de cooperação científica com a PUC de São Paulo, no qual se ressalta, entre outros aspectos, a importância dessa cooperação para o processo de reconhecimento do Serviço Social português como licenciatura ${ }^{1}$ e para a consolidação do estatuto técnico e científico do Serviço Social português.

\section{A formação em Serviço Social em Portugal}

A condição semiperiférica de Portugal, o desenvolvimento tardio do capitalismo nesse país e a permanência de relações sociais e modos

1 Em Portugal, a licenciatura é o grau máximo de formação no âmbito do primeiro ciclo, ou seja, na graduação. Um curso é reconhecido como curso superior universitário apenas se for certificado como licenciatura. Os cursos bacharéis não são considerados cursos universitários, mas cursos técnicos. 
de produção do tipo pré-capitalistas conferem particularidades aos processos de regulamentação, com práticas de solidariedade e base familiar em compensação e até substituição às ações do Estado. Essas características:

Reforçam o Estado como enquadramento analítico e o contexto de elucidação da trajectória do Serviço Social na sociedade portuguesa. Simultaneamente, sugerem uma particular articulação da ação estatal com as tradicionais formas de assistência (pela família, organizações religiosas e associações laicas de natureza filantrópica ou caritativa), com eventual expressão na formação acadêmica dos assistentes sociais e espaço de intervenção atribuído à profissão num dado contexto sócio-político (Martins, 1995, p. 44).

Diferenciando-se do modelo de intervenção de países democráticos e mais desenvolvidos do mundo ocidental, em Portugal, o denominado Estado Novo² (1933-1941) tinha a função de coordenar e fiscalizar as ações sociais realizadas pela iniciativa dos particulares, respondendo a manifestações da questão social com assistência corporativa e com forte influência da Igreja Católica. Esse foi o cenário da gênese e da institucionalização do Serviço Social em Portugal (Martins, 1995).

A proposta de criação de escolas de Serviço Social nos três principais centros urbanos do país, apresentada ao $2^{\circ}$ Congresso da União Nacional, ${ }^{3}$ culminou na criação do Instituto de Serviço Social de Lisboa em 1935 e, posteriormente, na fundação da Escola Normal Social em Coimbra, em 1937. Mais tarde, em 1956, deu-se a criação do Instituto de Serviço Social do Porto, pela Associação de Cultura e Serviço Social.

Estado Novo foi o regime ditatorial que vigorou em Portugal por 41 anos.

3 A União Nacional era o partido que detinha o monopólio da representação política no governo de Antonio de Oliveira Salazar, criado por decreto governamental em 1930 para substituir os partidos existentes. Mais informações, ver: Monteiro (1995) e Netto (1986). Nesse congresso, foi defendida a criação de escolas de Serviço Social pela Condessa de Rilvas (Carvalho, 2010, p. 150). 
Essas escolas portuguesas seguiam orientações da UCISS - União Católica Internacional de Serviço Social ${ }^{4}$ - e tinham natureza privada, no entanto, a direção política posta pelo Estado Novo exercia grande controle sobre essa formação, sobre a identidade profissional requerida e sobre a função do assistente social. Essas escolas foram regulamentadas pelo Estado em 1939 e, a partir desse marco, estabeleceu-se um plano de estudos de três anos que conferia o diploma e título do profissional Assistente Social. Nesse primeiro momento, a formação desse profissional tinha ênfase no estágio, que era desenvolvido ao longo dos três anos, priorizando-se a prática profissional, marcada por um viés higienista, fortemente doutrinário, corporativo e conservador (Branco, 2009).

Fatos históricos que se sucederam ao fim da Segunda Guerra Mundial e que foram relevantes para uma significativa mudança social, cultural e política no cenário mundial, tais como a publicação da Declaração de Direitos Humanos (1948) e a Convenção Europeia dos Direitos do Homem (1950), marcaram um novo contexto social e político nas décadas de 1950 e 1960 que trouxe implicações para o Serviço Social em Portugal, dentre estas, a reformulação de seu ensino.

Em Portugal, esse período seria marcado por profunda alteração das estruturas econômicas, dentre as quais se destacava a industrialização que seria incrementada com os Planos de Fomento ${ }^{5}$ e a abertura (forçada) à internacionalização da economia, por meio da adesão, em 1959, à EFTA (Associação Europeia de Livre Comércio). 0 momento apresentava também uma forte crise do regime político imposto por Salazar (1933/1974) que enfrentou tensões internas, oposições, conflitos e movimentos contestatórios da ditadura implantada sob seu governo e problemas sociais

4 A UCISS - União Católica Internacional de Serviço Social —, criada em 1922, com sede em Bruxelas, foi uma entidade confessional que reuniu escolas católicas de Serviço Social, associações católicas de assistentes sociais e membros individuais (Vieira, 1980, p. 51-53).

5 Em 1948, Portugal assinou o pacto fundador da OECE (Organização Europeia de Cooperação Económica), integrando-se às estruturas de cooperação previstas no Plano Marshall. A participação na OECE reforçou a necessidade de um planejamento econômico que conduziu à elaboração dos "Planos de Fomento" do Estado Novo. A esse respeito, consultar Lains (1994) e Rosas (1994). 
decorrentes desse processo. No bojo desse período, o Serviço Social viveu um momento de redimensionamento profissional.

A (re)orientaçao do Serviço Social para o terreno da Política Social inscreve-se e é formalmente sancionada por uma política educativa reorientada por relação ao poder econômico para a preparação da força de trabalho para a indústria, ou seja, como uma estratégia estatal de regulação do processo de proletarização em oposição ao poder ideológico da ortodoxia salazarista que se orientava para travar esse mesmo processo pela preservação dos quadros de vida típicos de sociedades pré-capitalistas (Monteiro, 1995, p. 59-60, grifos nossos).

O desenvolvimento do capitalismo e as questões associadas à urbanização e à industrialização exigiam agentes profissionais dotados de uma formação que apresentasse respostas mais eficazes às demandas profissionais. Estava posta, portanto, a necessidade de revisão curricular e do debate em torno da imprescindibilidade de o Estado assumir o ensino em Serviço Social que, até o momento, era ofertado apenas por escolas privadas.

Por mais que as orientações ideológico-doutrinárias ainda marcassem os conteúdos formativos e as propostas de alterações significativas tivessem sido interrompidas, a Revisão Curricular de 1956 foi considerada uma importante aproximação da formação em Serviço Social ao ensino superior, pois, a partir desse momento, as escolas disporiam de competência legal para a atribuição do diploma de curso superior. Além disso, com essa revisão se estabeleceu que a formação em Serviço Social, oficialmente, teria duração de quatro anos e se desencadeou um processo que veio a culminar no reconhecimento legal do Serviço Social como curso superior em 1961, mas ainda não universitário.

Nas reflexões sobre a profissão, nesse novo contexto do Serviço Social em Portugal, buscavam-se referências teórico-técnicas em aportes do Serviço Social norte-americano. Impunha-se à profissão, em Portugal, a modernização, sobretudo, para se atender às novas demandas recorrentes do agravamento da questão social, o que conduziu a um processo 
de tecnificação e maior aproximação às ciências sociais. Branco (2009) destaca que, apesar de sob o regime ditatorial as ciências sociais serem um campo censurado em Portugal, a formação nos institutos de Serviço Social, nomeadamente em Lisboa, constituiu um dos raros contextos acadêmicos nos quais se introduziu a formação em teoria social. ${ }^{6}$

O Serviço Social português, nesse momento, foi fortemente influenciado pelas novas orientações da política desenvolvimentista do período pós-guerra, expressas em projetos de cunhos comunitário e local, sob a égide de diferentes organismos internacionais, como a ONU. Branco (2009, p. 63) destaca a

[...] criação do Serviço de Proteção Social Comunitária e ao lançamento, em todo país, de diversos projetos de desenvolvimento local e comunitário. Esta orientação, estruturante e inovadora, de sentido desenvolvimentista, coexistirá com os domínios tradicionais do exercício do serviço social e, mormente com o serviço social corporativo e do trabalho, que consubstancia e orientação doutrinária e conservadora que se projeta da fase de institucionalização do serviço social em Portugal.

Foi nesse cenário desenvolvimentista, no qual se tornou necessária uma formação qualificada, com conhecimentos científicos que viessem a subsidiar ações de integração ao desenvolvimento econômico-social, que se registrou a primeira aproximação entre o Serviço Social brasileiro e o português. Este último teve acesso às produções bibliográficas do Serviço Social latino-americano, em especial as publicadas no final da década de 1960, bem como às bibliografias brasileiras correlatas aos seminários de teorização, sobretudo as referentes ao Seminário de Araxá (1967) e ao Seminário de Teresópolis (1970), publicadas na revista Debates Sociais do CBCISS - Centro Brasileiro de Cooperação e Intercâmbio de Serviços Sociais. Foi possível, também, o acesso aos livros de autores latino-americanos, como Vicente de Paula Faleiros, Ezequiel Ander Egg e Natalio Kisnerman.

6 O autor refere-se à aproximação com as ciências sociais. 
De acordo com Amaro (2012, p. 102), foi evidente a influência do pensamento desses autores e dessas referências ao Serviço Social brasileiro; a década de 1960 foi demarcada, entre outros aspectos, pelo que foi designado em Portugal como Serviço Social alternativo. ${ }^{7}$ Para a autora, mesmo que esse processo contestatório tivesse sido mais acentuado no período revolucionário (a partir de meados de 1970), já na década de 1960 foram criadas condições para o "questionamento, afirmação e cientifização do Serviço Social”.

Destaca-se que a relação com o Serviço Social da América Latina aconteceu por meio da circulação de publicações, artigos, livros e revistas relativas ao Movimento de Reconceituação, assim como pela presença de assistentes sociais latino-americanos que foram a Portugal ministrar aulas e cursos. ${ }^{8}$ Essa relação, para Amaro (2012), significou uma renovação do pensamento do Serviço Social em Portugal, uma nova forma de se encarar a intervenção do assistente social, na qual se destacaram o rompimento com a visão clássica norte-americana e o alinhamento às propostas do Serviço Social reconceitualizado da América Latina.

A formação em Serviço Social em Portugal, a partir dessa interlocução, recusou a neutralidade da profissão pautada na influência norte-americana e passou a ter influências de correntes marxistas, do pensamento crítico e do Movimento de Reconceituação (Martins, 2009).

Martins e Santos (2016b) ressaltam a importância dos encontros realizados pelas três escolas de Serviço Social que existiam até o ano de 1979 (Institutos Superiores de Serviço Social de Lisboa, Porto e Coimbra), com o fim de se reelaborar coletivamente os planos curriculares da formação

\footnotetext{
A expressão Serviço Social alternativo foi utilizada por Faleiros em discurso proferido, em 1980, aos formandos das Faculdades Metropolitanas Unidas, pois ele era o patrono da turma na ocasião. $O$ discurso foi publicado na revista Serviço Social \& Sociedade, n. 5, intitulado "Por um Serviço Social alternativo". O termo faz referência a uma profissão cujos valores se alinham à defesa dos direitos, próxima das periferias, participativa, a qual luta pela cidadania. Também Amaro (2012) faz menção a esse termo.

8 Pode-se citar como exemplo o seminário ocorrido em março de 1974 sobre "A reconceptualização do Serviço Social na América Latina”, orientado pelo Prof. Herman C. Kruze, com a presença de 67 participantes (Fernandes, 1985).
} 
a partir de um novo quadro teórico-ideológico. Nesse momento foram suscitadas, também, reflexões acerca da necessidade de maior organização da categoria na luta pelo reconhecimento da licenciatura no Serviço Social. Foi a partir desses marcos que se situou a relevância do protocolo entre o curso de Serviço Social da PUC-SP e as escolas portuguesas.

\section{Uma articulação política pela qualificação profissional dos assistentes sociais portugueses: o intercâmbio de cooperação científica com a Pontifícia Universidade Católica de São Paulo}

O período que se seguiu à Revolução dos Cravos (1974) ${ }^{9}$ foi, para o Serviço Social português, um período intenso de lutas pela carreira técnica superior, pela integração do ensino nas estruturas universitárias públicas, pelo reconhecimento do Serviço Social como licenciatura e pela qualificação dos quadros docentes, com a abertura dos cursos de mestrado e doutorado em Serviço Social, o que possibilitou um novo status profissional.

Nesse contexto, tornou-se relevante a luta pelo reconhecimento do Serviço Social como curso superior a partir de duas orientações: a integração da formação em Serviço Social nas universidades públicas, que até aquele momento eram as únicas a conferirem o grau de licenciatura (nível máximo de formação no âmbito da graduação); e o reconhecimento da formação existente, em escolas privadas, como grau de licenciatura (Branco, 2009). A partir de 1985, quando as estratégias pelo reconhecimento profissional foram redefinidas, ${ }^{10}$ se reiniciou um importante momento para o Serviço Social em Portugal que veio a culminar com a publicação do Decreto-lei n. 100-B/85, no qual foram estabelecidas regras de funcionamento dos cursos de ensino superior particular e cooperativo

\footnotetext{
9 A Revolução dos Cravos, ou Revolução de 25 de abril de 1974, foi a derrocada da ditadura fascista portuguesa que durou mais de 40 anos.

10 Sobre esse processo, consultar Negreiros (1991).
} 
existentes, o seu reconhecimento e a fiscalização da sua atividade. Até então, apenas cursos públicos poderiam conferir o grau de licenciatura; aos cursos particulares era possível conferir o grau de bacharel. Esse decreto se configurou em uma abertura à possibilidade de os cursos privados conferirem grau de licenciatura, mas impunha exigências em relação à qualificação docente e à obrigação de que houvesse um órgão de gestão científica e pedagógica, o que significou um obstáculo para os Institutos Superiores de Serviço Social — ISSS (Negreiros, 1991; Martins; Tomé, 2016).

Ainda em 1985, os ISSS de Lisboa e Porto entregaram, ao Ministério da Educação, o processo ${ }^{11}$ no qual requeriam, com base no decreto supracitado, a obtenção do grau de licenciatura. Nesse processo, apresentavam o novo Plano Curricular de cinco anos, que foi iniciado no ISSS de Lisboa em outubro de 1985 e, em outubro de 1986, no ISSS do Porto. Essas escolas, assumindo-se como Cooperativas de Ensino Superior, constituíram-se como instituições autônomas, de natureza não lucrativa, desvincularam-se das antigas estruturas de suporte jurídico-legal — ligadas à Igreja Católica - que lhes deram origem. Esse passo teve um significado de suma importância para a formação profissional em Serviço Social em Portugal:

[...] a formação separa-se definitivamente da sua origem confessional e é assumida pelo corpo de professores, alunos e trabalhadores não docentes, que se constituíram como base jurídica de suporte, arrogando-se como entidade laica (Negreiros, 1999, p. 271, grifos nossos).

Nessa nova perspectiva de formação, destaca-se o processo de readequação ${ }^{12}$ dos cursos de Serviço Social dos ISSS de Lisboa, Porto e Coimbra às exigências para a obtenção do grau de licenciatura. Esse processo foi grande impulsionador para o intercâmbio de cooperação científica entre

11 O ISSS do Porto entregou o processo em 16 de junho de 1985, e o ISSS de Lisboa, em 2 de agosto do mesmo ano. O ISSS de Coimbra não integrou esse processo, nesse momento, sustentando ainda a luta pela integração às universidades públicas.

12 A esse respeito, consultar Negreiros (1991, p. 273). 
a Pontifícia Universidade Católica de São Paulo - PUC-SP - e o Instituto Superior de Serviço Social de Lisboa e posteriormente do Porto, com o objetivo de qualificar o corpo docente dos dois institutos.

Segundo Rodrigues e Andrade (2009), o professor José Paulo Netto foi figura de destaque e teve interferência fundamental nesse processo. Como integrara por mais de um ano o quadro docente do ISSS de Lisboa, teve papel direto na articulação entre as duas escolas. 0 mesmo se deu com as professoras Úrsula Karsch (Brasil) e Maria Augusta Negreiros (Portugal), inicialmente responsáveis pelo protocolo.

Destarte, a PUC-SP assinou, em 23 de abril de 1986, um protocolo de cooperação e intercâmbio com o ISSS de Lisboa ${ }^{13}$ para cursos de mestrado e doutorado em Serviço Social. No ano de 1987, iniciou-se a primeira turma do curso de mestrado em Serviço Social ao abrigo desse protocolo.

Com esse curso de Mestrado criam-se as condições não só para a qualificação do corpo docente, como se introduzem avanços em ordem ao desenvolvimento da Investigação em Serviço Social, através dos projetos de pesquisa realizados no âmbito do próprio mestrado (Negreiros, 1986, p. 7).

Em 6 de novembro de 1987, foi realizada a celebração do protoco$10^{14}$ em abertura solene. ${ }^{15} \mathrm{Na}$ ocasião, a assistente social Maria Augusta Negreiros, representante do ISSS de Lisboa, proferiu discurso marcado por "mensagens" direcionadas aos órgãos governamentais em relação à luta pelo reconhecimento da licenciatura. Evidenciou-se, nesse discurso de abertura, o empenho para se apresentar o Serviço Social como

13 O discurso de abertura proferido pela diretora do ISSS de Lisboa, Profa. Maria Augusta, na íntegra, encontra-se na revista Intervenção Social, n. 1, 1986.

14 Detalhes da celebração e dos discursos proferidos, ver: revista Intervenção Social, n. 4, 1986. Nessa revista também estão disponíveis o Protocolo de Intercâmbio e os Planos de Estudos do Primeiro Mestrado. É importante se mencionar que há discrepância entre a data de publicação, que se refere ao ano de 1986, e o ano do próprio evento, em 1987. Ferreira (2006) observa que tal fato deve-se (por certo) ao atraso que a revista Intervenção Social sofria com frequência naquela época, mantendo-se, no entanto, quando da publicação, a sequência de numeração e ano.

15 A abertura solene do Primeiro. Mestrado foi realizada na Sala dos Espelhos do Palácio Foz, em Lisboa. 
[...] campo de conhecimento através da qualificação graduada e pós-graduada que permita "[...] acompanhar os acontecimentos teóricos a nível internacional e permitir uma qualidade de investigação que venha enriquecer ou alargar esse campo de conhecimentos na área do Serviço Social. [...] o assistente social, para intervir na sociedade atual e na complexidade dos problemas sociais que esta cria, necessita de um aprofundamento teórico, que proporcione a visão da relação entre os microfenômenos sociais e a macroestrutura da sociedade moderna" (Negreiros, 1986, p. 88, ${ }^{16}$, grifos nossos).

Firmado o protocolo com o ISSS de Lisboa, a PUC-SP reconheceu como licenciatura o curso de Serviço Social português, bem como se corresponsabilizou cientificamente pela legitimação deste, assegurando a participação de um professor doutor em Serviço Social no Conselho Científico do ISSS de Lisboa (Martins; Tomé, 2016).

$O$ curso de mestrado foi inscrito pelas agências de fomento à pesquisa dos dois países, CNPq (Conselho Nacional de Desenvolvimento Científico e Tecnológico), no Brasil, e JNICT (Junta Nacional de Investigação Científica e Tecnológica), em Portugal, tendo o segundo a disponibilizar bolsas de estudos a três dos 20 assistentes sociais que frequentaram o curso.

Em 1988, "reforçando e transformando este intercâmbio acadêmico com o Brasil numa rede de interconhecimentos" (Rodrigues; Andrade, 2009, p. 757), foi assinado o protocolo entre a PUC-SP e o ISSS do Porto (ISSSP), a partir do qual se viabilizou o I Curso de Mestrado em Serviço Social do ISSSP, oferecido em 1991.

Para Rodrigues e Andrade (2009), o protocolo firmado entre a PUC-SP e as escolas portuguesas foi essencial para o reconhecimento da licenciatura na formação de base existente em Portugal, para a consolidação de suporte científico e para a qualificação do corpo docente português.

16 Partes do discurso de Maria Augusta Negreiros, na ocasião da abertura solene do Primeiro. Mestrado em Serviço Social em intercâmbio com a PUC-SP, foram publicadas na revista Intervenção Social, n. 4, 1986. 
Sobre a importância do reconhecimento da licenciatura, Negreiros (1999, p. 295) afirma:

Com a atribuição do grau de licenciatura, aos Institutos de Lisboa e Porto, a formação acadêmica de Serviço Social dá um salto qualitativo em termos de legitimação e reconhecimento social, passando, em termos da Lei de Base do Sistema Educativo, a situar-se no quadro do Sistema universitário.

Esse reconhecimento se deu no bojo do intercâmbio construído a partir do protocolo com a PUC-SP, descrito no Plano de Estudos ${ }^{17}$ dos cursos de mestrado e doutorado em Serviço Social, cujos objetivos eram

- qualificar recursos humanos para a docência e pesquisa, em nível de pós-graduação, para os cursos de Serviço Social de Portugal, de forma a titular, em um período de 5 (cinco) anos, 20 pesquisadores e docentes;

- definir, programar e realizar, em regime de cooperação mútua, pesquisas de substancial importância para o desenvolvimento do Serviço Social de ambos os países;

- proporcionar aos docentes brasileiros e portugueses o intercâmbio de experiências e conhecimentos científicos entre o Brasil e Portugal, propiciando o fortalecimento recíproco da formação profissional em ambos os países;

- intensificar a publicação em língua portuguesa da produção científica do Serviço Social (Intervenção Social, n. 4, 1986).

Tais objetivos não eram apenas relacionados à formação específica de um número de assistentes sociais, mas também representavam um salto qualitativo que alavancaria a corrida pela obtenção da licenciatura

17 A coordenação geral, técnica e administrativa do programa esteve sob a orientação da Profa. Maria Augusta Negreiros, representando o ISSS de Lisboa, e da Profa. Myrian Veras Baptista, representando a PUC-SP. Contou com professores da PUC-SP para a área de Serviço Social, como Myriam Veras Baptista, Maria do Carmo Brant de Carvalho, Aldaíza Sposati, Maria Lúcia Carvalho da Silva, Úrsula Karsch, José Paulo Netto, Susana Aparecida da Rocha Medeiros, e com professores de universidades portuguesas para as outras áreas: José Madureira Pinto, Maria Manuela Silva e Fernando Farelo Lopes (Rodrigues; Andrade, 2009; Martins; Tomé, 2016). 
e do fortalecimento do Serviço Social português como área de pesquisa, que foi adensado com o criação do primeiro programa de doutoramento em Serviço Social, fruto de um segundo protocolo entre a PUC-SP e o ISSS de Lisboa, firmado em 1997, por meio de cooperação científica entre CAPES/MEC e o ICCTI - Instituto de Cooperação Científica e Tecnológica Internacional - , que foi vigente até o ano de $2001,^{18}$ denominado de "Missões". O plano de trabalho desse novo acordo de cooperação entre a PUC-SP e o ISSS de Lisboa objetivava oferecer a possibilidade de finalização da formação avançada para os mestres de então em Serviço Social dos institutos portugueses de Lisboa e Porto, que haviam obtido sua titulação ao abrigo do protocolo entre as universidades citadas. ${ }^{19}$

Trata-se de um Programa Especial, ${ }^{20}$ concebido para atender à realidade do Serviço Social português neste momento peculiar de sua trajetória, em que busca consolidar o seu estatuto acadêmico e científico, e contribuir, de forma cada vez mais plena, para o processo de desenvolvimento nacional e para a inserção de Portugal na União Européia. ${ }^{21}$

Uma contribuição fundamental do programa de doutoramento foi a realização do projeto de pesquisa vinculado ao programa e intitulado Configurações contemporâneas da questão social: repercussões nas políticas sociais e no processo de trabalho do Serviço Social brasileiro e português, cujo objetivo era a realização de um estudo comparado entre as realidades política, social e econômica de ambos os países, procurando

18 Informações obtidas por acesso aos documentos referentes ao convênio intitulado "Projeto Integrado CAPES/ICCTI. Programa especial de doutorado em Serviço Social (1998/2001) Brasil (PUC-SP) - Portugal (ISSSL)". Acesso gentilmente disponibilizado pela Profa. Dra. Maria Carmelita Yazbek em reunião realizada no dia 8 de junho de 2018, na PUC-SP.

19 Conforme documento intitulado "Projeto Integrado CAPES/JNICT", gentilmente cedido pela Profa. Dra. Maria Carmelita Yazbek.

20 O programa foi apoiado pela PRODEP — Preparação e Desenvolvimento Profissional.

21 Conforme documento intitulado "Projeto Integrado CAPES/JNICT", de 1997, gentilmente cedido pela Profa. Dra. Maria Carmelita Yazbek (grifos nossos). 
apreender as novas manifestações da questão social no contexto das transformações do fim do milênio. ${ }^{22}$

Ressalta-se que a estrutura curricular dos cursos de mestrado e doutorado em Portugal era muito similar à do currículo da PUC-SP. O corpo docente, apesar de representar uma mescla de professores brasileiros e portugueses, privilegiava a atribuição das disciplinas específicas para os primeiros e estes levavam consigo o projeto de formação do Brasil, do recém-aprovado currículo de 1982, quando do protocolo para os cursos de mestrado (em 1987), e, posteriormente, das recém-aprovadas Diretrizes Curriculares da ABEPSS (Associação Brasileira de Ensino e Pesquisa em Serviço Social) de 1996, por ocasião do protocolo para os cursos de doutorado, em 1997.

Destarte, o projeto de formação, oriundo do protocolo entre a PUC-SP e o ISSS de Lisboa, contemplava o "acervo de reflexões e questões que no Brasil se tinham vindo a configurar em anos recentes" (Rodrigues; Andrade, 2009, p. 759) e que aproximava os dois países, apesar de "tanto mar" os separar.

A qualificação acadêmica possibilitada pelo protocolo com a PUC-SP criou uma geração de docentes pós-graduados em Serviço Social e novos cursos de mestrado e doutorados próprios das escolas portuguesas. Em 1995, foram criados os primeiros programas de mestrado em Serviço Social, sob a responsabilidade de instituições de ensino portuguesas - os ISSS de Lisboa ${ }^{23}$ e de Porto - reconhecidas pelo Ministério da Educação de Portugal (Branco; Rodrigues, 2009).

Além da qualificação dos docentes das escolas de Serviço Social em Portugal, outra contribuição de fundamental importância do protocolo entre a PUC-SP e o ISSS de Lisboa foi o incentivo à investigação científica, à pesquisa em Serviço Social, à produção do conhecimento nessa área, que foi possível a partir das reflexões e publicações provenientes dos cursos

22 Conforme o documento intitulado "Projeto Integrado CAPES/JNICT", gentilmente cedido pela Profa. Dra. Maria Carmelita Yazbek.

23 Conforme a Portaria do Ministério da Educação n. 182, de 6 de março de 1995. 
de mestrado e doutorado em intercâmbio com a PUC-SP. Essa questão fica evidente quando se analisam os números referentes a dissertações e teses publicadas a partir do convênio com a PUC-SP. Foram concluídos 49 trabalhos, sendo oito teses e 41 dissertações elaboradas no período de 1989 a dezembro de 2003, 14 foram produzidas sob o protocolo com a PUC-SP entre os anos de 1989 e 1998 (oito do primeiro mestrado e seis da segunda turma) e 27 já se referiam ao mestrado do ISSS de Lisboa, cujo período de produção data de 1998 a 2003.

Outro aspecto de relevância nesse processo foi a criação de Núcleos de Pesquisa, dentre os quais se destaca o "Núcleo de Investigação em História do Serviço Social Português", no âmbito do qual se desenvolve o projeto coletivo "A construção do conhecimento do Serviço Social português”. Salienta-se, também, o Núcleo de Investigação em História do Serviço Social Português formalizado na criação do CPIHTS - Centro Português de Investigação em História e Trabalho Social. Esse centro manteve protocolos de cooperação científica com outros centros de investigação, em âmbito nacional, como o CISSEI $^{24}$ - Centro de Investigação em Serviço Social e Estudos Interdisciplinares - e a AIDSS ${ }^{25}$ - Associação de Investigação e Debate em Serviço Social do Porto - e, em âmbito internacional, com a Universidade do Chile e com a PUC-SP.

Em documento ${ }^{26}$ no qual o protocolo entre o CPIHTS e a PUC-SP foi firmado, as instituições concordaram em promover a cooperação entre si nas áreas de interesse mútuo por meio das seguintes atividades: intercâmbio de professores e de pesquisadores; condução de projetos de pesquisa conjuntos; organização de eventos e simpósios; intercâmbio de informações e de publicações acadêmicas; e intercâmbio de estudantes.

O centro foi pioneiro na divulgação de teses de doutorado, dissertações de mestrado, trabalhos finais de cursos de graduação, atas de jornadas e seminários por ele organizados e livros de autores, bem como produziu

\footnotetext{
24 Para mais informações ver: Ferreira (2006).

25 Para mais informações, ver Ferreira (2006).

26 Documento gentilmente cedido pela Profa. Dra. Maria Carmelita Yazbek em reunião realizada na PUC-SP, na data de 8 de junho de 2018.
} 
edições luso-brasileiras (CPIHTS e Veras Editora) e criou, em 1995, a revista internacional Estudos \& Documentos, publicada em sua página virtual.

O CPIHTS conta atualmente com 25 pesquisadores, entre eles, alguns brasileiros. ${ }^{27}$ Em 2001, o CPIHTS tomou posição pública junto à FCT Fundação para a Ciência e Tecnologia —, em prol do reconhecimento do Serviço Social como área de conhecimento e domínio científico autônomo, no entanto, a área só veio a ser contemplada na Classificação de Domínios Científicos e Tecnológicos como subárea da Sociologia em 2007, ainda marcada pela subalternização a outras áreas das ciências sociais.

Ressalta-se, enfim, que a parceria com a PUC-SP representou, para o Serviço Social português, o início de um novo ciclo, um período marcado pela busca intensa de qualificação e reconhecimento do Serviço Social, não apenas como licenciatura, mas também uma luta pelo reconhecimento deste como profissão e área de conhecimento em Portugal.

\section{Considerações finais}

É consenso entre os autores portugueses, ${ }^{28}$ com os quais concordamos, que a produção do conhecimento em Serviço Social em Portugal é um processo muito recente e embrionário, e que o caminho percorrido até aqui teve significativas contribuições do protocolo estabelecido com a PUC-SP na década de 1980. Nesse processo, destaca-se o período que se inicia no final da década de 1980; segundo as análises deste artigo, esse é o período em que a relação entre o Serviço Social brasileiro e o português é mais contundente.

Como se observa nas reflexões apresentadas neste artigo, a interlocução entre o Serviço Social brasileiro e o português, acentuada com

27 Professores brasileiros que fazem parte da equipe de pesquisadores do CPIHTS: José Paulo Netto, Maria Liduina de Oliveira e Silva, Maria Lúcia Barroco, Myriam Veras Baptista (ainda constante no site, apesar de seu falecimento em 19/9/2015) e Vicente de Paula Faleiros. Disponível em: www.ciphts.com.

28 Entre eles: Martins (1998); Branco e Rodrigues (2009); Ferreira (2006); Martins e Tomé (2016); Martins e Carrara (2014). 
o protocolo entre a PUC-SP e as escolas portuguesas, foi decisiva para o reconhecimento da licenciatura em Serviço Social em 1989. Ademais, é explícito que esse protocolo possibilitou a qualificação do corpo docente em Serviço Social de Portugal, nas suas diferentes escolas, bem como qualificou assistentes sociais "da ponta", contribuindo para a diminuição da distância entre a academia e os espaços sócio-ocupacionais do Serviço Social em Portugal.

Por meio da qualificação do corpo docente das escolas portuguesas, do incentivo e da contribuição direta do protocolo com a PUC-SP, foi possível a abertura de programas de pós-graduação, mestrado e doutorado próprios das escolas portuguesas, os quais até os dias atuais contam com a participação de professores brasileiros em disciplinas, seminários e outros eventos.

Por fim, destaca-se que a parceria firmada entre a PUC-SP e as escolas portuguesas fomentou a pesquisa, a investigação e a produção do conhecimento em Serviço Social por meio dos grupos de pesquisa, protocolos de cooperação científica (como é o caso do CPIHTS e a PUC-SP), bem como publicações ${ }^{29}$ e grupos de pesquisas que unem universidades brasileiras e portuguesas ${ }^{30}$ ainda hoje.

Destarte, compreende-se que a parceria entre o Serviço Social brasileiro e o português é na contemporaneidade uma possibilidade a ser construída diante de novos contextos sócio-históricos, em ambos os países. Observa-se a construção de tendências teórico-metodológicas diversas em ambos os países no que tange à concepção das atribuições dos assistentes sociais e à perspectiva de ensino em Serviço Social. Seguem, contudo, novas possibilidades de interlocução a serem trilhadas.

29 Por exemplo, o livro Serviço Social Portugal-Brasil: formação e exercício profissional em tempos de crise, organizado por Alcina Martins, Claudia Mônica dos Santos, Dulce Serra Simões, Jorge Ferreira e Marcelo Braz.

30 Por exemplo, o Projeto "Investigação, formação e trabalho em Serviço Social em Portugal e no Brasil”, inscrito no Centro de Estudos da População, Economia e Sociedade (CEPESE), por investigadores do Instituto Superior Miguel Torga (Coimbra/Portugal), da UFRJ (Universidade Federal do Rio de Janeiro, RJ/Brasil) e da UFOP (Universidade Federal de Ouro Preto, Minas Gerais/Brasil) (Martins; Tomé, 2016). 


\section{Referências}

AMARO, Maria Inês. Urgências e emergências do Serviço Social: fundamentos da profissão na contemporaneidade. Lisboa: Universidade Católica Portuguesa, 2012.

BRANCO, Francisco. A profissão de assistente social em Portugal. Lócus Soci@l, Lisboa, n. 3, 2009.

BRANCO, Francisco; RODRIGUES, Fernanda. A investigação em Serviço Social em Portugal: uma aproximação a partir da formação pós-graduada. Lócus Soci@l, Lisboa, n. 2, 2009.

CARVALHO, Maria Irene Lopes Bogalho. Serviço Social em Portugal: percurso cruzado entre a assistência e os direitos. Serviço Social e Saúde, Campinas, v. 9, n. 10, dez. 2010.

FERNANDES, Ernesto. Elementos para uma cronologia do Serviço Social em Portugal. Intervenção Social, Lisboa, n. 2-3, 1985.

FERNANDES, Ernesto; MARINHO, Manuela; PORTAS, Manuela. O Serviço Social na Europa: a experiência portuguesa. Intervenção Social, Lisboa, n. 22, 2000.

FERREIRA, Maria Emília. Serviço Social e construção do conhecimento: contextos, lógicas e significados no Serviço Social. 2006. Tese (Doutorado em Serviço Social) — Pontifícia Universidade Católica, São Paulo, 2006.

INTERVENÇÃO SOCIAL. Lisboa: ISSSL, n. 4, 1986.

LAINS, Pedro. O Estado e a industrialização em Portugal, 1945-1990. Análise Social, Lisboa, v. 29, n. 128, p. 923-995, 1994.

MARTINS, Alcina. Gênese, emergência e institucionalização do Serviço Social português - a escola normal de Coimbra. Intervenção Social, Lisboa, n. 11, 1995.

MARTINS, Alcina. Serviço Social e investigação. In: NEGREIROS, Maria Augusta Geraldes et al. Serviço Social: profissão e identidade: que trajectória? Lisboa: Veras, 1998. (Cadernos do Futuro).

MARTINS, Alcina. 70 anos de formação em Serviço Social em tempos de ditadura e de democracia: da escola normal superior ao Instituto Miguel Torga. Interações, Campo Grande, n. 17, p. 21-44, 2009.

MARTINS, Alcina Maria de Castro; CARRARA, Virgínia. Serviço Social português e brasileiro em diálogo: internacionalização da formação profissional. Em Pauta, Rio de Janeiro, v. 12, n. 33, p. 205-227, 1. sem. 2014.

MARTINS, Alcina Maria de Castro; SANTOS, Cláudia Mônica dos. Tendências críticas na formação do assistente social em Portugal. In: MARTINS, Alcina et al. (org.). Serviço Social Portugal - Brasil: formação em tempos de crise. Campinas: Papel Social, 2016a.

MARTINS, Alcina Maria de Castro; SANTOS, Cláudia Mônica dos. A formação do assistente social em Portugal: tendências críticas em questão. Katálysis, Florianópolis, v. 9, p. 324332, out./dez. 2016b. 
MARTINS, Alcina; TOMÉ, Rosa. Serviço Social português e Serviço Social brasileiro: 50 anos de contribuições históricas. In: SILVA, Maria Liduina de Oliveira (org.). Serviço Social no Brasil: histórias de resistência e de ruptura com o conservadorismo. São Paulo: Cortez, 2016. p. 365-388.

MONTEIRO, Alcina. A formação acadêmica dos assistentes sociais: uma retrospectiva crítica da institucionalização do Serviço Social no "Estado Novo". Intervenção Social, Lisboa, n. 11, 1995.

NEGREIROS, Maria Augusta. Discurso proferido na ocasião da assinatura do Protocolo de Intercâmbio entre a Pontifícia Universidade Católica de São Paulo e o Instituto Superior de Serviço Social. Intervenção Social, Lisboa, n. 4, p. 97-107, 1986.

NEGREIROS, Maria Augusta. Licenciatura em Serviço Social: elementos principais de um processo. Intervenção Social, Lisboa, n. 5, p. 101-110, 1991.

NEGREIROS, Maria Augusta. Serviço Social: uma profissão em movimento. A dinâmica acadêmico-profissional no Portugal pós-74. 1999. Tese (Doutorado em Serviço Social) Pontifícia Universidade Católica, São Paulo, 1999.

NETTO, José Paulo. Portugal: do fascismo à revolução. Porto Alegre: Mercado Aberto, 1986.

RODRIGUES, Fernanda; ANDRADE, Marília. Intercâmbio de produção de conhecimentos Brasil e Portugal em tempos de viragem. Serviço Social \& Sociedade, São Paulo: Cortez, n. 100, p. 593-594, out./dez. 2009.

ROSAS, Fernando. O Estado Novo (1926-1974): história de Portugal. Lisboa: Estampa, 1994. v. 7.

VIEIRA, Balbina Otoni. História do Serviço Social: contribuição para a construção de sua teoria. 3. ed. Rio de Janeiro: Agir, 1980.

\section{Sobre as autoras}

Kathiuscia Freitas Coelho - Professora adjunta do Departamento de Serviço Social. Doutorado em Serviço Social e Política Social.

E-mail: kathiuscia.as@gmail.com

Olegna de Souza Guedes - Professora adjunta do Departamento de Serviço Social. Doutorado pela Pontifícia Universidade Católica de São Paulo e pós-doutorado em Ciências Sociais pela Universidade Estadual Paulista (Unesp).

E-mail: olegnasg@gmail.com 